\title{
Carnets
}

Revue électronique d'études françaises de l'APEF

Deuxième série - 15 | 2019

Jules Verne et les pouvoirs de l'imagination

\section{Do imaginário em Jules Verne}

Perspectivas da ciência

Isabel Malaquias

\section{(2) OpenEdition}

Journals

Edição electrónica

URL: http://journals.openedition.org/carnets/9173

DOI: $10.4000 /$ carnets. 9173

ISSN: 1646-7698

Editora

APEF

\section{Refêrencia eletrónica}

Isabel Malaquias, « Do imaginário em Jules Verne », Carnets [Online], Deuxième série - 15 | 2019, posto online no dia 31 janeiro 2019, consultado o 01 maio 2019. URL : http://journals.openedition.org/ carnets/9173; DOI : 10.4000/carnets.9173

Este documento foi criado de forma automática no dia 1 Maio 2019.

\section{(c) (i) (8)}

Carnets est mis à disposition selon les termes de la licence Creative Commons - Atribution - Pas d'utilisation commerciale 4.0 International. 


\title{
Do imaginário em Jules Verne
}

\author{
Perspectivas da ciência
}

\author{
Isabel Malaquias
}

\section{Públicos para a ciência}

1 A criação de públicos para a ciência remonta aos ideais do período iluminista, em que as máquinas /instrumentos de demonstração ilustravam as novas propriedades da matéria (electricidade, vazio, magnetismo, ...) e os amadores demonstradores itinerantes pululavam e contribuíam diversamente para o desenvolvimento das ciências experimentais. A consolidação e institucionalização da ciência e das disciplinas científicas, durante o século XIX, desenvolveu novos caracteres profissionais, diferentes especialidades e preocupações com a educação e construção de um público alargado para a ciência.

2 Por volta de 1780, o filósofo e matemático francês Nicolas de Condorcet (1743-1794), membro da Académie des Sciences de Paris, debruçando-se sobre o papel das academias científicas, considerava que estas eram centros profissionais da ciência onde, mediante a independência e poder que detinham, resultantes do talento, saber e competência científicas, era possível exercer simultaneamente uma liberdade face à opinião popular e também face ao capricho dos governantes. Nesta dupla missão, e porque havia uma forte vigilância pelos pares, era possível encontrar a função de uma academia científica, que deveria ser fórum de académicos, e não de civis, que julgaria os seus próprios membros e a ciência que faziam, salvaguardando os bons métodos e evitando o abandono de um qualquer ramo. A academia atribuía-lhes assim um lugar na sociedade (McClellan, 1977 : 241-6). Desta forma, Condorcet que, enquanto político, advogava o poder público e o sufrágio universal, estabelecia para a Academia a autoridade de denunciar a charlatanice e a imposição da verdade no que à ciência dizia respeito, como acontecera com os casos de Jean-Paul Marat (1743-1793), contestando Newton, ou Franz Mesmer (1734-1815), com a teoria do magnetismo animal e suas alegações parapsicológicas. Bensaude-Vincent (2000) aponta a importância particular da Academia francesa, cuja interdependência do Estado era notória e que, mesmo após a revolução de 1793, agora na versão de Institut de France, 
mantinha, senão aumentara, os seus poderes, que se estendiam até à escolha dos professores da École Polytechnique, controlando toda a vida científica.

3 No início do século xix, a academia era, assim, um campo muralhado que procurava resistir à pressão do público, considerando-se a defensora da legitimidade da ciência, numa dimensão superior à da opinião pública - «a opinião do sábio não é da mesma ordem da do cidadão », donde resulta que a ciência académica tem o «monopólio da opinião esclarecida pela livre discussão e pelo pensamento crítico », enquanto a opinião popular é apanágio de todos os restantes cidadãos (Bensaude-Vincent, 2000 : 70-1).

Bensaude-Vincent (2000: 73-95) regista o ano de 1835 como marco de debate destas questões, na medida da convergência de dois episódios que releva : os encontros semanais da Academia que passam a ser registados nos Comptes-rendus hebdomadaires de l'Académie des Sciences, por proposta de François Arago (1786-1853) e a vinda a público do segundo volume do Curso de Filosofia Positiva de Auguste Comte (1798-1857).Ambos obtiveram a sua formação na École Polytechnique, mas trilharam percursos diferentes. Por um lado, Arago, defensor de opiniões liberais e republicanas, secretário perpétuo da Academia, já em 1835, e por outro Comte, fundador do positivismo, visando o dogmatismo científico, preterido na entrada para a École Polytechnique e depois para a Academia. Ambos deram cursos de astronomia popular, em Paris : Arago no Observatoire, desde 1813, com grande sucesso e Comte, numa associação politécnica destinada ao ensino de operários, fundada na sequência da revolução de 1830. Comte fará do seu curso um empreendimento revolucionário, ciente de que a opinião pública tem de controlar a ciência que se faz e afastar controvérsias inúteis que dividem os estudiosos, pela sua presença nos debates científicos. Enquanto advoga a 'ordem dogmática' para o ensino das ciências,

5 Não há liberdade de consciência em astronomia, em física, em química, em fisiologia, declarava no seu primeiro artigo em 1822, no sentido de que cada um acharia absurdo não acreditar nos princípios estabelecidos nestas ciências pelos indivíduos competentes Comte adopta a 'ordem histórica' no ensino popular (Bensaude-Vincent, 2000 : 82).

Pelo contrário, Arago tem uma atitude de carácter liberal e aberta, apresentando os resultados da ciência. Por outro lado, propondo a criação dos Comptes Rendus, redigidos pela Academia, Arago consegue ultrapassar as questões surgidas durante as sessões académicas, onde os jornalistas acorriam em busca de novidades, tendo entrado em conflito com alguns académicos, e suscitando da parte de alguns destes a recusa em participar das mesmas. Desta forma, a imprensa ficava controlada pela Academia e, simultaneamente, introduzia-se uma escrita mais simples e directa, em sintonia com a existência de uma publicação mais rápida (Bensaude-Vincent, 2000 ; Nieto-Galan, 2011).

Em breve, vai também assistir-se a um apelo à produtividade científica, na medida em que se altera a ideia de homem de ciência, passando este a ter um estatuto de trabalhador da ciência, logo, responsável pela produção de resultados úteis (Schlanger, 1997: 116; Bensaude-Vincent, 2000 : 78).

Paralelamente ao desenvolvimento das ciências e actividade industrial, durante o século XIX, deu-se particular atenção à generalização do ensino elementar, à criação de escolas secundárias e técnicas, e também de universidades. No entanto, quer por razões ideológicas quer por necessidades da economia e da formação de trabalhadores, gerou-se a ideia de ser preciso completar a acção da escola com uma difusão extra dos progressos das ciências e das técnicas. 
7 Jules Verne introdu-las habilmente nos seus romances, embora outros se interessem por elas e enalteçam as suas maravilhas, incluindo-se numa corrente favorecida pela difusão da leitura e da instrução elementar. Publicam-se dicionários, tornando-se famoso o de Pierre Larousse (1817-1875) - Le Grand Dictionnaire Universel, surgido entre 1863 e 1876, com a pretensão de apresentar ao público o essencial sobre aspectos científicos, históricos e práticos. Entre outros autores referem-se Louis Figuier (1819 -1894), autor de Les Merveilles de la Science, ou Description Populaire des Inventions Modernes, de entre uma obra mais vasta, Jean-Henri Fabre (1823-1915), com várias publicações sobre entomologia e outros temas, Camille Flammarion (1842 -1925), autor prolixo cuja Astronomie populaire (1879) obteve um sucesso considerável, bem como Abbé François Moigno (1804-1884) (Crozon 2005 : 70).

8 Nem todos são cientistas, embora busquem informação a partir dos melhores autores, mas existem os que o são, e reputados, como Arago, Liebig (1803-1873), Agassiz (1807-1873), Jacques Babinet (1794-1872) e mesmo Berthelot (1827-1907), que não desdenham divulgar os seus trabalhos em obras populares. Outros, como Pasteur (1822-1895), recusam-se a fazê-lo, preferindo intervir junto de um público seleccionado. Terá, no entanto, ocasião de admitir a importância que os publicistas têm na mobilização da opinião em prol da ciência.

9 A vulgarização científica não foi assumida de igual modo em países como a Inglaterra ou o Canadá, por exemplo. Nestes, a comunidade científica, em particular os seus expoentes, envolveu-se e trouxe a ciência para a sociedade. A imprensa científica encontrava-se nas mãos das sociedades instruídas ou dirigida por cientistas profissionais. Um exemplo bemsucedido foi o da revista semanal Nature, fundada em 1869 pelo astrónomo Norman Lockyer (1836-1920) em aliança com o editor Alexandre McMillan (1818-1896), da Macmillan Publishers.

10 Em França, sucedeu precisamente o contrário, com poucas excepções como referido, estando a vulgarização científica a cargo dos publicistas e escritores científicos, que se dedicam afincadamente à mesma.

Por outro lado, enquanto no caso francês se verifica um movimento do centro para a periferia, no caso inglês o mesmo é variado. A fundação da Royal Institution (1799) criou o polo londrino de abertura da ciência ao público, mas ao mesmo tempo verifica-se que há um desenvolvimento paralelo nas regiões industrializadas a partir de determinações locais, por vezes proveniente dos próprios industriais que pretendem ter empregados mais experientes e qualificados e suscitam a oportunidade de estes beneficiarem de uma educação para adultos, nomeadamente em assuntos técnicos, por exemplo através dos Mechanics Institutes, a que se acrescem as actividades dos conferencistas itinerantes. De realçar que a primeira Associação para o Avanço das Ciências (BAAS) é criada em 1831 com a intenção declarada de promover o conhecimento científico, e torná-lo público, numa altura em que não existia ainda qualquer infraestrutura governamental, educacional ou industrial para a ciência, em Inglaterra. Assim, era seu objectivo

to give a stronger impulse and more systematic direction to scientific inquiry; to obtain a greater degree of national attention to the objects of science, and a removal of those disadvantages which impede its progress; and to promote the intercourse of the cultivators of science with one another, and with foreign philosophers (BAAS, 1860: s.p.).

11 A partir do momento em que a ciência se torna um objecto oferecido ao consumo de massas, há necessidade de perceber que, neste momento um leitor assíduo de revistas de 
vulgarização ou de enciclopédias pode tornar-se sábio, embora isso não corresponda ao seu envolvimento na produção de saber. Os investigadores profissionais são bem distintos dos que possuem o saber, sejam eles amadores, professores ou eruditos. Numa terminologia algo económica, distingue-se o 'sector de produção' dos 'sectores de consumo - seja a escola ou a vulgarização'. Em contrapartida, a vulgarização apresenta também "um retorno sobre a ciência", pois à medida que as investigações se tornam mais áridas e difíceis de acompanhar pelo público, os publicistas têm de transformar o discurso e amenizá-lo perante o público, de forma a manter o interesse deste pela ciência. As escritas são necessariamente diferentes e à escrita científica, transparente e cumpridora das regras do método de crítica e replicação por pares, contrapõe-se a escrita de divulgação que apresenta «os resultados independentemente do percurso que permite estabelecê-los » (Bensaude-Vincent, 2000 : 123-40).

Ao saber complexo, árduo, formal, inacessível, contrapõe-se o cenário da « simplicidade grandiosa, majestosa», apresentando os cientistas como "artistas esventrando os segredos da natureza ao fogo do seu génio » (Bensaude-Vincent, 2000 : 123-40).

Assim, a "ciência para todos" aparece como contrapeso epistemológico da especialização e da formalização das ciências, concorrendo ambas para a construção do saber (BensaudeVincent, 2000 : 123-40).

A admiração de Jules Verne (1828-1905) pela ciência e a sua confiança na inteligência humana é manifesta nos seus romances científicos e geográficos. $\mathrm{E}$, em boa verdade, descobertas e invenções importantes surgiram ao tempo. Ocorreram no interior da própria ciência, afectaram a tecnologia e emergiram na sociedade, em propostas inovadoras que alteraram as comunicações, a indústria, o conforto quotidiano dos cidadãos. Simultaneamente, desenvolvia-se uma classe trabalhadora citadina a que os movimentos sociais e políticos procuravam responder.

Os avanços da ciência ao tempo de Jules Verne conjugam-se com a transformação dos meios de produção, resultantes da Revolução Industrial, que, da sua origem em Inglaterra, se expandia agora pela Europa e América. Transformavam-se as relações laborais, os modos de vida, as cidades, as relações sociais, as ideologias.

Verne testemunhou muitas destas transformações e na sua obra traduz muitos destes aspectos. Natural de Nantes, onde a agitação do seu porto comercial terá contribuído para alimentar a sua imaginação criadora, Verne terá passado muitas horas livres a observar a azáfama dos navios, a chegada de mercadorias exóticas, o bulício de tripulações e passageiros. Refere-se a importância dessa época, mas também a sua avidez de informação, frequentando posteriormente, em Amiens, a biblioteca da Sociedade Industrial, leitor assíduo de novidades científicas. Alguns contactos estabelecidos foram particularmente importantes, com o explorador Jacques Arago (1790-1855), em 1850, irmão de François Arago, com Nadar em 1860, dois anos após este ter realizado a primeira fotografia aérea, e em 1862 com aquele que veio a ser o seu editor, Pierre-Jules Hetzel (1814-1886). Através deste conheceu e estabeleceu amizade com alguns cientistas, como o químico Henri Sainte-Claire Deville (1818-1881), o matemático e professor da École Polytechnique Joseph Bertrand (1822-1900), o fisiologista e professor do Muséum National d'Histoire Naturelle Louis-Pierre Gratioler. Aconselhando-o teve ainda ao seu lado Paul, seu irmão e antigo oficial de marinha, bem como Henri Garcet, seu primo e professor de Matemática, e ainda Albert Badoureau, o seu amigo engenheiro de minas (Dekiss, 2005 : 9-27). 


\section{Alguns marcos da ciência e tecnologia ao tempo de Jules Verne}

Os progressos da indústria, as novas invenções técnicas acompanharam e/ou suscitaram o desenvolvimento científico, que transformou completamente as condições de vida.

Relembraremos algumas em particular, no seguimento e na linha cronológica, com indicação de alguns dos romances de Verne (Figura 1).

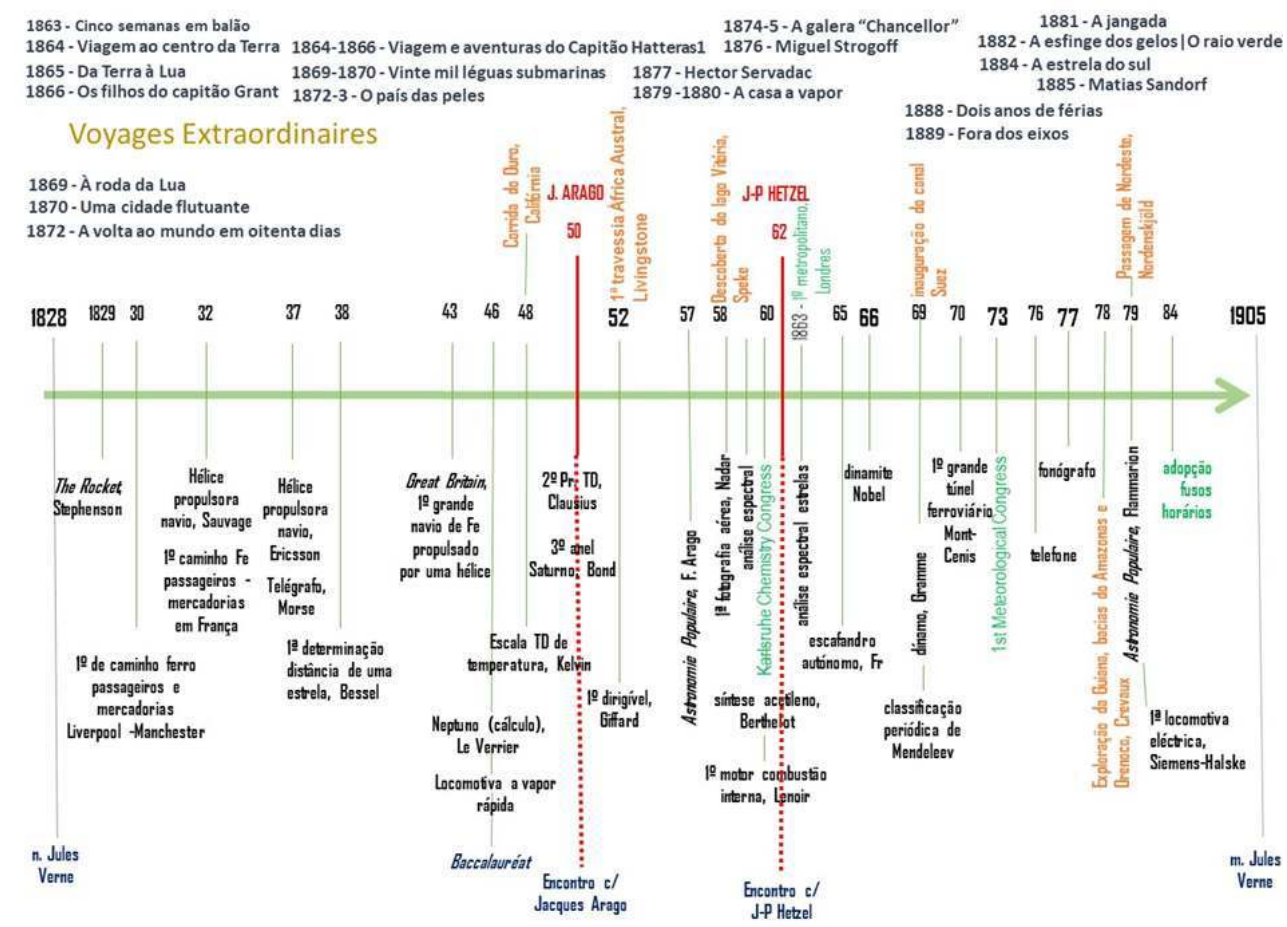

Em 1830, inaugurava-se a primeira linha ferroviária, entre Liverpool e Manchester, que fazia uso exclusivo da energia a vapor e transportava simultaneamente passageiros e mercadorias. Foi a primeira linha a ser totalmente de via dupla em toda a sua extensão, a ter um sistema de sinalização e um horário completo anunciado, bem como a primeira a levar correspondência. Constituiu um marco histórico no desenvolvimento das comunicações terrestres.

O trabalho sobre locomotivas a vapor vinha sendo feito desde finais do século XVIII, tendo Trevithick (1771-1833) construído a primeira de grande escala (1802). No caminho de ferro Liverpool-Manchester, fazia-se uso do modelo de locomotiva a vapor de Stephenson (1781-1848), construída em 1829. Esta reunia vários aperfeiçoamentos, de entre os quais a existência de um par dianteiro de grandes rodas motrizes, accionadas por dois cilindros laterais posicionados angularmente, sem que as rodas traseiras lhes estivessem acopladas. Este modelo vigorou por cerca de 150 anos na maior parte das máquinas a vapor. Em 1832, inaugura-se em França o primeiro caminho de ferro de passageiros e mercadorias, a linha de Saint-Étienne a Lyon (Brun et Bernard, s.d. : en ligne).

O emprego da hélice propulsora e sua aplicação nos navios vai revolucionar este meio de transporte, registando-se em 1840 o lançamento do primeiro navio a hélice, o Britannia, que fez a travessia Liverpool - Nova Iorque. 
Os registos fotográficos sofreram avanços significativos entre 1839 e 1840, essencialmente com os contributos de Daguerre (1787-1851), Nièpce (1765-1833), Fox Talbot (1800-1877) e de Hércules Florence (1804-1879).

O desenvolvimento matemático da mecânica racional, no final do século xvIII, veio criar as condições de previsibilidade de posições e velocidades de diferentes tipos de projécteis, suscitando uma visão determinista e calculável de efeitos. Em 1846, o astrónomo francês Urbain Le Verrier (1811-1877) deduziu a existência de um novo planeta, Neptuno, o mais afastado de todos os planetas até então conhecidos, e calculou a sua posição e trajectória, que Johann Gottfried Galle (1812-1910) e Heinrich Louis d'Arrest (1822-1875) observaram pela primeira vez em Setembro desse ano em Berlim. Pouco tempo depois, em 1851, o físico francês Léon Foucault (1819-1868) demonstrava a rotação da Terra, sem recurso a referenciais externos, através da experiência do pêndulo suspenso na abóbada do Panthéon, que viria a ter o seu nome. A observação astronómica veio evidenciar a existência de vários asteroides entre Marte e Júpiter e, a partir de 1838, publicaram-se as primeiras medidas de distâncias estelares. Os instrumentos tornavam-se cada vez mais sofisticados e a fotografia veio possibilitar observações até então inacessíveis.

Outras áreas buscavam o conhecimento que lhes permitisse adquirir a previsibilidade conseguida com a mecânica racional : calor e mudanças de estado dos corpos, fenómenos eléctricos, acústicos, luminosos, caloríficos. Vingava a teoria ondulatória da luz, com os trabalhos franceses de E.-L. Malus (1775-1812), F. Arago, J.-B. Biot (1774-1862) e A. Fresnel (1788-1827). Seguindo sugestões de Arago, Foucault e Fizeau (1819-1896) realizam investigações sobre a interferência da luz e do calor. Fizeau mede a velocidade da luz no vazio e na água, com uma aproximação até então desconhecida. A brilhante integração dos fenómenos electromagnéticos e luz em quatro equações celebrizarão o inglês J.-C. Maxwell (1831-1879), a partir de 1864, transformando a plêiade destes fenómenos em algo sintetizável de forma elegante e matemática. Fenómenos que terão aplicações tecnológicas de alcance social, com o desenvolvimento da indústria eléctrica e a transformação da energia mecânica em energia eléctrica e vice-versa. A invenção do dínamo, em 1869, por Z. Gramme (1826-1901) permitiu a obtenção de correntes contínuas, tendo-se verificado, algum tempo depois (1873) ser possível a obtenção de energia mecânica, fazendo a alimentação eléctrica do mesmo dínamo. Tornava-se também possível a utilização de hídricas para a produção de corrente eléctrica, fazer o transporte desta e usá-la posteriormente em máquinas, nas cidades e povoações. A electricidade tornava-se um bem de grande interesse para as novas comodidades que chegam, dos transportes às comunicações com a invenção de diferentes dispositivos e aparelhos que modificam profundamente a vida quotidiana : a telegrafia (1835), o telefone (c. 1860), o fonógrafo (1877), as lâmpadas de incandescência (1879), a telegrafia sem fios (1897), exemplos do modernismo tecnológico que Jules Verne vai inserindo nos seus romances, ou que lhe permitem antever futuras aplicações.

19 Todos os ramos da física clássica atingem níveis de qualidade teórico-experimentais até então nunca vistos, ao mesmo tempo que surgem novas questões associadas às propriedades mais íntimas da matéria (descoberta dos raios catódicos, raios $\mathrm{x}$, radioactividade).

20 A evolução da química terá também um percurso marcante no desenvolvimento da indústria europeia, em particular com o sucesso da química orgânica, a síntese dos primeiros corantes sintéticos, a destilação da hulha a partir de cuja fracção gasosa foi possível obter o gás de iluminação, que tornou a noite dia nas ruas, na indústria e como 
combustível doméstico, mas também novos compostos obtidos a partir das outras fracções que, por sua vez, servirão de matéria-prima a muitos outros compostos.

Em 1869, o estabelecimento por D. Mendeleev (1834-1907) da classificação periódica dos elementos, utilizando o critério de pesos atómicos crescentes, veio permitir uma conceptualização dos elementos conhecidos e criar o critério de previsão de novos elementos, o que veio a verificar-se pouco tempo depois.

Foi ainda no âmbito da química orgânica que se descobriram os explosivos nitrados, primeiro a nitrocelulose e o algodão-pólvora (1845) e depois a nitroglicerina (1846) que, em 1866, Alfred Nobel (1833-1896) consegue estabilizar como dinamite.

Preparam-se diferentes substâncias novas, como por exemplo a aspirina, em 1853, diferentes essências artificiais, que serão utilizadas na perfumaria e nas indústrias alimentares (1875) ; produzem-se diversos compostos para antissepsia.

A obtenção do alumínio e o conhecimento das suas propriedades apontou-o como uma matéria-prima importante, embora os processos para a sua obtenção fossem difíceis e dispendiosos.

22 A borracha tem as suas propriedades mecânicas valorizadas depois da invenção da vulcanização, em 1839, pelo americano Charles Goodyear (1800-1860), vindo a ter uma utilização importante na indústria de bicicletas e do automóvel, que viriam a desenvolver-se alguns anos mais tarde.

Em 1868, obtém-se pela primeira vez o celuloide, o primeiro material artificial, antecessor dos plásticos.

A conservação dos alimentos teve alguns progressos, com a descoberta dos princípios da fermentação e do processo de pasteurização. Em 1850, o instrumentalista Ferdinand Carré (1824-1900) concebeu a primeira máquina de produção de gelo, posteriormente aperfeiçoada e vulgarizada até surgirem os primeiros frigoríficos por volta de 1870 . 0 impacto desta invenção irá ser enorme permitindo a conservação e transporte de alimentos a nível mundial.

É ainda durante o século XIX que o conhecimento do globo terrestre atinge um patamar nunca atingido, colocando-se em confronto teorias sobre a sua formação e a percepção de que a idade da Terra é muito superior à considerada até então. Fazem-se observações sistemáticas dos movimentos da crusta terrestre, chegando-se à noção (c. 1855) de que os constituintes mais leves da crusta flutuam sobre um manto líquido denso e viscoso.

23 A publicação de Kosmos (1845-1862), de Alexandre Humboldt, veio trazer a público uma tentativa de descrição física abrangente do que se sabia até então no campo da geografia geral, geomorfologia, climatologia, geomagnetismo e descrição dos caracteres geológicos à escala global.

24 A exploração oceânica revela a existência de vida a grande profundidade e também a importância das correntes marítimas.

Será de relembrar ainda que, entre 1878 e 1900, Paris acolheu três exposições universais e que, para cada uma, foram reunidos recursos para produzir cidades dentro da própria cidade. Os responsáveis pela sua organização recorreram aos desenvolvimentos científicos e tecnológicos mais modernos e com alcance internacional. A relação de reciprocidade desenvolvida entre a cidade 'da luz' e estas feiras constituiu uma cultura de mudança de base científica e tecnológica para gerir o futuro (Levin, 2010). 


\section{Do imaginário em Jules Verne} fazer a passagem entre os imaginários científico e literário, evidenciando que em ambos se procura ver diferentemente o que nos rodeia, seja uma planta, um ser vivo, um rio, mas também procurando a ligação de cada coisa às outras (Serres, 2003). Na análise de Serres, as Voyages extraordinaires de Verne ilustram a passagem da infância à idade adulta, um começo, qual Telémaco viajante, razão porque Verne se contava entre os grandes mestres, influenciador de várias gerações : a viagem marcava o fim da adolescência. 0 projecto educativo de Jules Verne bebe sobretudo em Hetzel, seu editor que, com Jean Macé, estabelece uma casa editora dedicada à educação enciclopédica e moral, duas dezenas de anos antes das leis educativas promulgadas por Jules Ferry (1832-1893), evidenciando-se como precursores. Do ponto de vista da história das ciências, interessa perceber porque é que de repente diferentes sociedades como a francesa, a inglesa, a alemã ou a italiana «tiveram necessidade de renovar nessa altura as questões da educação, ou melhor da difusão ». O enorme desenvolvimento das ciências e das técnicas invadiu o quotidiano e Verne integra « uma cadeia que, saída das mais altas instâncias da investigação, mergulha no grande público », adaptando essa difusão (Serres, 2003 :12-16). Em Jouvences, Sur Jules Verne, Serres (1774) havia-se debruçado sobre a viagem, relembrando as de Ulisses e Homero para chegar a Laplace, e Augusto Comte, como que da "lenda à ciência", em que o antepassado escreve a viagem que depois é necessário decifrar, do que se ocupará a ciência (Serres, 1974 :21). Como se articulam em Verne « a poesia dos mitos, a ciência dos homens e suas viagens »? Serres busca nos primeiros textos conhecidos da nossa cultura as aventuras do "herói que parte à procura da imortalidade " (Serres, 2003 :12-16). A Odisseia e a Eneida têm este papel e com elas se institui a pedagogia.

Verne soube incluir-se na escola de Augusto Comte. Tal como num mapa, a legenda explica como ler os símbolos que se encontram indicados. As ciências têm as suas legendas que é preciso conhecer para poder lê-las. Nesse sentido, propõe uma via: « constrói uma máquina que permite ir e ver» (Serres, $2003: 21-26)$, seja mediante um submarino que viabiliza conhecer a vida subaquática, seja através de um obus que roda em torno da Lua ou um pedaço de continente arrancado à Terra que deambula por entre os planetas do sistema solar, como acontece em Hector Servadac ou na Jangada, que desce lentamente o Amazonas e permite explorar as suas margens e encontrar os seus habitantes.

Verne fatia o mapa-mundo e cada uma das suas histórias é uma parte dele. A geografia destes itinerários permanece uma ciência a descobrir. As Voyages extraordinaires de Verne destacam, entre outros, territórios como a Livónia, os Cárpatos, o Québec e, no interior destes espaços, desenham um itinerário. 0 mesmo acontece nas circum-navegações, por exemplo em Os filhos do capitão Grant ou A volta ao mundo em 80 dias (Serres, 1974 : 56 ; 2003 : 24).

Conduzir a infância ao longo de uma viagem, tal a etimologia da palavra pedagogia. Será assim que se visitam as ciências. Para conhecer a totalidade da enciclopédia, percorre-se a totalidade do mundo. Verne aponta duas cartografias, primeiro a do mundo e depois a do saber, a que sobrepõe "um mapa misterioso do espaço imaginário" (Serres, $2003: 25)$.

Não antecipa sobre a ciência, esclarecerá Serres (1974: 82), pois a que refere é já conhecida desde meados do século através de Comte, mas, « porque faz funcionar o mito e a 
pedagogia em conjunto, antecipou a nossa sociedade » (Serres, $2003: 26$ ).

A omnipresença dos meios de comunicação (balões, aeróstatos, submarino, máquinas a vapor, aviões, caminhos de ferro) fá-lo-ão prospectivar, pois retornam de um modo recorrente e sustentado, antecipando um estado da sociedade, que não a ciência. Verne tenta prever duas coisas : "tal ou tal meio de comunicação" e a "interface da sociedade com as novas técnicas". Em A volta ao mundo em 80 dias, por exemplo, Phileas Fogg utiliza quase todos os meios : comboio, barco a vapor e à vela. Em Miguel Strogoff, no auge de uma batalha, apresenta-nos Harry Blount, o jornalista inglês, e o seu adversário francês Alcides Jolivet rivalizando no uso do telégrafo eléctrico (Serres, 1974 : 148 ; 2003 : 95-96).

Parece ainda antecipar a procura pela definição de 'um novo estar do homem sobre a Terra', através das suas grandes personagens, como Hatteras, Nemo, Sandorf, Robur o Conquistador.

A presença da ciência, mesmo quando não fala dela, caracteriza a sua obra.

\title{
Notas finais
}

A vida de Jules Verne acompanha o extraordinário desenvolvimento científico e tecnológico do século xIx, de que ele faz eco nos seus vários romances, ou de que antevê possibilidades futuras, que terão também eles um impacto extraordinário nas sociedades de vários países, contribuindo para o papel de divulgação tão caro e requerido pela sociedade e cientistas da época, embora assumindo características diferentes, se tivermos em atenção a França de Verne ou, por exemplo, a Inglaterra de então. As gerações de leitores de Jules Verne foram muitas, pelo que terminaremos com as palavras apropriadas de Charles Lepierre (1867-1945), um francês cuja vida pessoal e científica decorreu em Portugal,

\author{
*** \\ À Jules Verne \\ La jeunesse universelle reconnaissante (Lepierre, 1927)
}

\section{BIBLIOGRAFIA}

BENSAUDE-VINCENT, Bernadette (2000). L'opinion publique et la science - À chacun son ignorance. Paris: Institut d'édition Sanofi-Synthélabo.

BRITISH ASSOCIATION FOR THE ADVANCEMENT OF SCIENCE (1860). Report on twenty-ninth meeting of the British Association for the Advancement of Science, held at Aberdeen in 1859 / British Association for the Advancement of Science. London. In https://www.rct.uk/collection/1090676/ report-on-twenty-ninth-meeting-of-the-british-association-for-the-advancement-of. Consultado em Outubro de 2018

BRUN, Daniel, Bernard, Jean-Philippe (s.d.). « Chemins de Fer », Encyclopcedia Universalis [en ligne], consulté le 2 janvier 2019. URL : http://www.universalis.fr/encyclopedie/chemins-de-fer/ 
CROzON, Michel (2005). «Um século de progressos », in Phillipe de la Cotardière, Jean-Paul Dekiss (dir.). Júlio Verne - Da ciência ao imaginário. Rio de Mouro : Círculo de Leitores, pp. 34-70.

DEKISS, Jean-Paul (2005). « Uma vida, uma obra », in Phillipe de la Cotardière, Jean-Paul Dekiss (dir.). Júlio Verne - Da ciência ao imaginário. Rio de Mouro : Círculo de Leitores, pp. 9-27.

LEPIERRE, Charles (1927). Jules Verne - Auteur d'une oeuvre de paix. Lisbonne : s.ed., 10 p.

LEVIN, Miriam R. (2010). « Modernizing Paris through expositions and museums », in Ana Cardoso de Matos, Irina Gouzévitch, Marta C. Lourenço (dir.). Expositions universelles, musées techniques et société industrielle - World Exhibitions, Technical Museums and Industrial Society.Lisboa : Edições Colibri, CIDEHUS-UE, CIHUCT, pp. 115-124.

MCCLLELLAN, James E. (1977) «Un manuscrit inédit de Condorcet: Sur l'utilité des academies », Revue d'histoire des sciences, tome 30, numéro 3, pp. 241-253.

NIETO-GALAN, Agusti (2011). Los públicos de la ciencia - Expertos y profanos a través de la historia.

Madrid : Marcial Pons, Ediciones de Historia, S.A.

SCHLANGER, Judith (1997), La Vocation. Paris : Seuil.

SERRES, Michel (2003). La science et l'homme contemporain. Paris : Éditions Le Pommier.

SERRES, Michel (1974). Jouvences, Sur Jules Verne. Paris : Les Éditions de Minuit.

\section{RESUMOS}

O século XIX foi um século particularmente frutífero no que respeita a ciência e suas aplicações tecnológicas, em que o emergir de públicos para a ciência teve lugar a partir do crescimento e dinamismo da imprensa escrita, de situações de crítica à ciência que se fazia, do entusiasmo em democratizar o saber perante uma população proletarizada, do desenvolvimento da educação secundária e científica e ainda pelo interesse em participar na própria construção da ciência (sociedades astronómicas, botânicas, ...). A vida de Jules Verne (1828-1905) perpassa praticamente todo o século e a sua obra constitui-se como uma grande aventura, através da qual encontramos a referência e a narrativa imaginária que as novidades científico-tecnológicas suscitavam nos personagens que criou, ainda crentes nas maravilhas do progresso.

Abordaremos aspectos que foram fundamentais no desenvolvimento da ciência e tecnologia da época e que terão estado presentes em alguns romances de Jules Verne.

The nineteenth century was a particularly fruitful century concerning science and its technological applications. The emergence of publics for science took place from the growth and dynamism of the written press, from situations of criticism to the science done, and the enthusiasm in democratizing knowledge before a worker population, the development of the secondary and scientific education, and from the interest in participating in the very construction of science (astronomical, botanical societies ...). Jules Verne's life (1828-1905) runs through almost the entire century and his work is a great adventure, through which we find the reference and the imaginary narrative that the scientific-technological novelties elicited in the characters he created, still believers in the marvels of progress.

We will cover aspects that were fundamental in the development of science and technology of the time and will have been present in some Jules Verne's novels. 
ÍNDICE

Keywords: Verne (Jules), publics for science, science and technology, scientific culture, nineteenth century

Palavras-chave: Verne (Jules), públicos para a ciência, ciência e tecnologia, cultura científica, século XIX

\section{AUTOR}

\section{ISABEL MALAQUIAS}

Departamento de Física, CIDTFF

Universidade de Aveiro

imalaquias[at]ua.pt 